\title{
Candida glabrata's Genome Plasticity Confers a Unique Pattern of Expressed Cell Wall Proteins
}

\author{
Eunice López-Fuentes ${ }^{1}$, Guadalupe Gutiérrez-Escobedo ${ }^{1}$ (1), Bea Timmermans ${ }^{2,3}$, \\ Patrick Van Dijck ${ }^{2,3}$ (i), Alejandro De Las Peñas ${ }^{1(1)}$ and Irene Castaño $1, *$ (i) \\ 1 Instituto Potosino de Investigación Científica y Tecnológica (IPICYT), División de Biología Molecular, \\ Camino a la Presa San José 2055, San Luis Potosí, SLP 78216, Mexico; eunice.lopez@ipicyt.edu.mx (E.L.-F.); \\ maria.gutierrez@ipicyt.edu.mx (G.G.-E.); cano@ipicyt.edu.mx (A.D.L.P.) \\ 2 KU Leuven, Laboratory of Molecular Cell Biology, Kasteelpark Arenberg 31 bus 2438, 3001 Leuven, Belgium; \\ bea.timmermans@kuleuven.vib.be (B.T.); patrick.vandijck@kuleuven.vib.be (P.V.D.) \\ 3 VIB-KU Leuven Center for Microbiology, 3001 Leuven, Belgium \\ * Correspondence: icastano@ipicyt.edu.mx; Tel.: +52-444-8342038; Fax: +52-444-8342010
}

Received: 9 May 2018; Accepted: 3 June 2018; Published: 5 June 2018

\begin{abstract}
Candida glabrata is the second most common cause of candidemia, and its ability to adhere to different host cell types, to microorganisms, and to medical devices are important virulence factors. Here, we consider three characteristics that confer extraordinary advantages to C. glabrata within the host. (1) C. glabrata has a large number of genes encoding for adhesins most of which are localized at subtelomeric regions. The number and sequence of these genes varies substantially depending on the strain, indicating that C. glabrata can tolerate high genomic plasticity; (2) The largest family of CWPs (cell wall proteins) is the EPA (epithelial adhesin) family of adhesins. Epa1 is the major adhesin and mediates adherence to epithelial, endothelial and immune cells. Several layers of regulation like subtelomeric silencing, cis-acting regulatory regions, activators, nutritional signaling, and stress conditions tightly regulate the expression of many adhesin-encoding genes in C. glabrata, while many others are not expressed. Importantly, there is a connection between acquired resistance to xenobiotics and increased adherence; (3) Other subfamilies of adhesins mediate adherence to Candida albicans, allowing C. glabrata to efficiently invade the oral epithelium and form robust biofilms. It is noteworthy that every C. glabrata strain analyzed presents a unique pattern of CWPs at the cell surface.
\end{abstract}

Keywords: Candida glabrata; cell wall proteins; adherence; virulence; fluconazole resistance; genome plasticity; subtelomeric silencing; clinical isolates

\section{Introduction}

Fungal invasive infections have become increasingly frequent in hospitals worldwide, in part, as a result of higher numbers of immunocompromised patients. Bloodstream infections are particularly dangerous since they are associated with high mortality rates [1]. In immunocompromised patients, Candida species are the most commonly isolated fungal species from bloodstream infections (candidemia) in the US, of which Candida albicans is the most frequently found species followed by Candida glabrata [2,3]. Candidemias have remained stable over the last decade but several studies report decreasing frequency of $C$. albicans and increases of other non-albicans species. Among these species, C. glabrata is of particular concern since it is innately less susceptible to azoles [4,5]. Alarmingly, some studies have found resistance to echinocandin class of antifungals among the already azole resistant C. glabrata clinical isolates in the US [6].

Adherence to different cells and surfaces is considered a crucial virulence factor in pathogens. In this regard, C. glabrata in part owes its success as a pathogen to the ability to adhere tightly to 
several types of mammalian host cells (epithelial, endothelial and immune cells), to other microbes (bacteria and other Candida species), and to medical devices and to form complex structures called biofilms. The frequency with which each of these species is isolated from patients, correlates with the number of genes encoding a specific class of Cell Wall Proteins (CWPs) called adhesins. The genome of C. glabrata contains an unusually large repertoire of cell wall protein-encoding genes, many of which are adhesin-like encoding genes. These proteins have the conserved structure of surface exposed CWPs (see below). In the C. glabrata reference genome there are 66 genes encoding adhesin-like proteins. The number of these genes and the CWPs actually displayed at the cell wall varies widely between clinical isolates of $C$. glabrata. Some of these clinical isolates contain up to 101 adhesin-encoding genes in their genomes [7-10].

In this review we will focus on the EPA (Epithelial adhesin) family of genes, emphasizing the large variability between different $C$. glabrata strains regarding the number of genes present per genome. We will describe the important role played by the major adhesins Epa1, Epa6, and Epa7 in mediating adhesion to host cell tissues, medical devices, and other microbes, and their unique expression pattern.

\section{Role of Adherence during Infection}

\subsection{Adherence in Candida glabrata Is a Virulence Factor}

Adherence to human host tissues and medical devices like catheters is thought to be the first step in the development of an infection caused by $C$. glabrata. This leads to colonization and invasion of the sterile tissues of the host. C. glabrata has been shown to adhere tightly to several types of mammalian cells such as, (1) epithelial cell lines derived from various organs (Lec2, HEp2, CHO, and HeLa among others) [11-13]; (2) coronary endothelium, endothelial cell lines as HBEC, HRGEC, and other endothelial cells [13-15]; (3) different types of immune cells like macrophages, natural killer, and dendritic cells [16-18]. C. glabrata also binds to some components of the host extracellular matrix like fibronectin (through an identified fibronectin receptor) [19] and laminin-332 [20,21]. In addition, C. glabrata can also form complex communities called biofilms that are adhered to different surfaces and embedded in an extracellular matrix. For example, C. glabrata can make biofilms on vascular and urinary catheters, cardiac devices like prosthetic valves and pacemakers (reviewed in [22]). The role of adhesins in the different stages of biofilm formation is discussed in another review in this volume [23]. The ability to adhere to different host tissues or surfaces allows C. glabrata cells to persist in a nourishing host niche, or to form protective biofilms to resist antifungal drugs. Thus, adherence is considered a very important virulence factor [24].

\subsection{Adherence Is Mediated by Cwps in C. glabrata}

The fungal cell wall is the first point of interaction with the environment. In C. glabrata, the cell wall contains a wide variety of so-called CWPs classified into two large groups based on type of bond with which they are associated to the cell wall: (a) Proteins linked through a mild alkali-sensitive linkage to $\beta$-1,3-glucan (Pir proteins), and (b) proteins containing glycosylphosphatidylinositol (GPI) modified anchor covalently bound to the $\beta-1,6$-glucan $[25,26]$.

Pir (protein with internal repeats) proteins contain an N-terminal signal peptide for secretion, a Kex2 protease cleavage site, a central domain with a variable number of tandem repeats which are $\mathrm{O}$-glycosylated, and a C-terminal region containing four cysteine residues [26,27]. GPI-modified CWPs comprise a large family of proteins exposed at the cell surface and covalently bound to the cell wall. Adherence of fungal cells is generally mediated by adhesins, which belong to the GPI-anchored class of proteins. Fungal adhesins consist of four general domains. (1) A signal peptide at the N-terminus for secretion; (2) The functional N-terminal domain is involved in ligand binding, which can recognize carbohydrates or protein ligands, depending on the particular adhesin; (3) The N-terminal domain is followed by a low complexity domain, which contains a variable number of repeated motifs of amino acids, which usually are rich in serine and threonine and is highly glycosylated; (4) The C-terminal 
end contains a GPI addition signal that is responsible for covalent crosslinking of the protein to the cell wall $[13,28-30]$.

\subsection{C. glabrata Shows High Variability in the Number and Sequence of CWP-Encoding Genes}

Initial sequencing of the C. glabrata genome (strain CBS138 or ATTC 2001, here referred to as CBS138), in 2004 [31], revealed the presence of many putative CWP-encoding genes in comparison with the benign and closely related yeast Saccharomyces cerevisiae [10]. C. glabrata belongs to the Nakaseomyces genus, which comprises two subgroups. C. glabrata is part of the second subgroup (called the "glabrata group") composed by C. glabrata, N. delphensis (a non-pathogenic species), and C. bracarensis and C. nivariensis. These last two species are closely related to C. glabrata and have been isolated from patients, albeit at a much lower frequency than C. glabrata [32]. The Epa family of adhesins encoded by the EPA genes confers this ability to adhere to epithelial and endothelial cells $[11,13,33,34]$. In fact, the capacity to colonize and produce disease in the human host coincides with the expansion of the EPA genes in C. glabrata compared to the nonpathogenic N. delphensis, C. castellii, and N. bacillisporus [32,35]. In different strains of $C$. glabrata isolated from patients worldwide there is an enormous variability in the number and type of adhesin-encoding genes. In some recently sequenced clinical isolates, about $1.3 \%$ of the genome encodes putative CWPs [7] and some other isolates contain 101 adhesin-like genes [10].

It is noteworthy that high levels of homologous, nonallelic recombination can account for some of the variability. The majority of these genes are located at subtelomeric regions where recombination can occur $[24,36]$. The genetic variation found between these isolates mainly affects CWPs. These genes accumulate many rearrangements such as deletions and duplications, thus behaving as recombinational hotspots [7].

\subsection{Adherence to a Variety of Surfaces Is Mediated by the Presence of a Large Family of (GPI)-Modified Proteins at the Cell Surface}

Based on a phylogenetic tree of the ligand binding N-terminal domain of adhesins, these can be divided into seven subgroups designated clusters I through VII. The EPA and the PWP genes conform two homogeneous subfamilies to which only EPA or PWP genes belong. The AWP (Adhesin-like wall protein) genes and other adhesin-like encoding genes belong to the 5 other different subfamilies [28]. There is little relationship between the N-terminal domains of clusters III-VII [25,28]. The EPA genes (cluster I) belong to the largest subgroup of adhesins with 18 genes in the sequenced strain CBS138 [31] and 23 in the laboratory standard strain BG2 [37]. Even among the orthologues of EPA genes between these two standard strains, there is high variability as the orthologues are not identical in sequence [28].

The Pwp family of adhesins (cluster II) is composed of at least seven members (Pwp1-7), and their $\mathrm{N}$-terminal domain shares similarity to the corresponding domain of the Epa proteins, particularly in the conserved PA14 domain (Anthrax protective antigen) [28]. Pwp7 has been shown to mediate adherence to endothelial cells [14] and could also play a role in aggregation.

Proteomic analysis of CWPs covalently bound to the cell wall of several C. glabrata strains identified six proteins of the Awp group: Awp1-6 [25,38]. A recent subsequent proteome analysis of highly hyperadherent clinical isolates discovered 6 novel adhesins of the Awp family: Awp8, Awp9, Awp10, Awp11, Awp12, and Awp13 [8].

Many of the adhesin-like CWPs of C. glabrata, including Epas, Awps, and Pwps, contain a variable number of repeated motifs of the VSHITT or SFFIT sequence. These repeats conform mega-satellites, which are unusually long tandem repeated sequences that are only present in C. glabrata [28,39]. The number of repeats in these mega-satellites has an impact on the length of the CWP and in some cases a larger number of repeats in the mini-satellites has been correlated with increased adherence, flocculation, or biofilm formation [40]. 


\subsection{EPA Family}

As stated above, the largest family of CWPs is the Epa family of adhesins. Most of the EPA genes are located in subtelomeric regions $[33,34]$. The first member discovered of this family was EPA1, which encodes for the major adhesin in vitro in C. glabrata (Epa1) [11]. Epa1 N-terminal, ligand-binding domain, shares the PA14 domain present in many carbohydrate-binding lectins. The role of Epa1 in vivo is also important, as several studies have found increased expression of EPA1 [12,41,42], but other adhesins must also play important roles since epa1 $\Delta$ strains display no defect in colonization phenotype in a mouse model of systemic infection [11]. Also, there are examples of highly adherent isolates that do not show high levels of EPA1 expression [8,9,43].

Epa6 and Epa7 have also been shown to be functional adhesins involved in kidney and bladder colonization in vivo [33,44]. When Epa1, Epa6, and Epa7 are heterologously expressed in the non-adherent $S$. cerevisiae, they confer adherence to epithelial and endothelial cells in vitro and to other organisms as well $[11,13,33]$. Epa1, Epa6, and Epa7 bind carbohydrates containing a terminal galactose residue, although the specificity varies for these three adhesins [13]. The ligand binding specificity and the classification of Epa N-terminal subtypes is described in detail in [23] in this issue.

\section{Regulation of Expression of EPA Genes}

\subsection{Subtelomeric Silencing and Cis-Acting Elements Regulate the Expression of EPA Genes}

In general, adhesins are not constitutively expressed. It is possible that differentially regulated CWPs enable C. glabrata to change its adhesion capacity and adapt to the different abiotic surfaces, human tissues, or other microorganisms [8]. All the sequences adjacent to the telomeres of the sequenced CBS138 strain contain at least one putative adhesin-encoding gene [25]. The majority of the EPA genes are localized at these subtelomeric regions and this localization implies in some strains, like $\mathrm{BG} 2$, that the expression of the EPA genes is controlled by chromatin-based subtelomeric silencing [33,34]. Subtelomeric silencing is a regional and global transcriptional repression independent of the identity of the gene [45]. In C. glabrata, subtelomeric silencing requires the SIR complex (Sir2, Sir3, and Sir4), Rif1, Rap1, and yKu proteins (yKu70 and yKu80) and can extend $>20 \mathrm{~kb}$ away from the telomere $[34,44,46]$. However, different telomeres in C. glabrata have different protein requirements for silencing. For instance, the proteins yKu70 and yKu80 are not required in the right telomere of the chromosome E (E-R $)$ where the EPA1 forms a cluster with EPA2 and EPA3 [46]. Furthermore, not all of the C. glabrata strains display an efficient negative regulation by subtelomeric silencing of the EPA genes as in the BG2 strain. Among a collection of 79 clinical isolates, 11 were found to be hyperadherent under conditions where most of the EPA genes are silenced in the BG2 strain. Analysis of the SIR3 sequence of the hyperadherent isolates, revealed several polymorphisms that could account for a less efficient protein to establish or maintain subtelomeric silencing in the hyperadherent strains [12]. In this work, the CBS138 strain was found to be hyperadherent and the SIR3 gene shares some of the polymorphisms identified in the hyperadherent clinical isolates [12].

In addition to the $\mathrm{Chr} \mathrm{E}_{-\mathrm{R}}$, silencing has been tested in other telomeres of $C$. glabrata. The EPA4 and EPA5 genes are located in the right telomere of chromosome I ( $\left.\mathrm{Chr} \mathrm{I}_{-\mathrm{R}}\right)$. These genes form an almost perfect inverted repeat and subtelomeric silencing can propagate at least $24 \mathrm{~kb}$. Silencing in this subtelomeric region depends on Rap1, Sir complex, Rif1, and yKu proteins [34,46]. In addition, silencing at both ends of chromosome $\mathrm{C}$, where EPA6 and EPA7 are located, depends on the SIR complex and $\mathrm{yKu}$ proteins $[33,46]$. Therefore, at least in some C. glabrata strains, subtelomeric silencing is a global regulatory network which plays an important role in the expression pattern of the adhesins-encoding genes.

In this regard, even though many EPA genes are silenced, their expression can be induced under different environmental conditions. This specific induction of EPA expression could have important implications in terms of adaptation to nutritional and oxidative stress or the presence of xenobiotics encountered in different host niches. Thus, C. glabrata cells could respond to changing environmental 
conditions by expressing a different set of CWPs. For example, in strain BG2, EPA6 is induced during urinary tract infections due to low levels of nicotinic acid, a precursor of $\mathrm{NAD}^{+}$. The histone deacetylase Sir2, which is part of the SIR complex and essential for silencing of subtelomeric regions, requires $\mathrm{NAD}^{+}$for its enzymatic activity. Since $C$. glabrata is an auxotroph of nicotinic acid, a milieu with low concentrations of $\mathrm{NAD}^{+}$results in inactivation of Sir2, relief of silencing, and expression of EPA6 [44]. $E P A 2$ expression is induced by the transcription factors Yap1 and Skn7 under conditions of oxidative stress [47]. EPA1, EPA3, EPA7, and EPA22 are expressed during biofilm formation [38] and EPA3 is also highly induced by osmotic stress and glucose starvation [48].

\subsection{EPA1 Is Tightly Regulated by Cis-Acting Elements}

EPA1 is located close to the right telomere of chromosome $\mathrm{E}\left(\mathrm{Tel} \mathrm{E}_{-\mathrm{R}}\right)$, where it forms a cluster with EPA2 and EPA3 (Figure 1). Under most laboratory conditions, EPA1 gene in the BG2 strain is not expressed, but it can be induced during the lag phase, immediately after a stationary phase culture is diluted into fresh media. Activity of the EPA1 promoter is then negatively regulated by a cis-acting element, called the negative element (NE), which requires the yKu proteins and represses EPA1 expression during logarithmic phase. There are nine additional copies of the NE in the CBS138 genomic sequence, some of which are associated to EPA genes, including EPA6 and EPA7. We have shown that the expression of these genes is also negatively regulated by their associated NEs and independently of the vicinity of the corresponding telomere (Figure 2) [49]. Furthermore, EPA1 expression is also negatively regulated by subtelomeric silencing, which is independent of the regulation of the NE [49]. In addition to these two mechanisms, this subtelomeric region contains a protosilencer, called Sil2126, localized between EPA3 and the telomere, which helps propagate the heterochromatin assembled at the telomere repeats for up to $20 \mathrm{~kb}$ (Figure 1). Sil2126 has unique properties in that it is only active when placed close to its native telomere (Tel E-R), but inactive at similar distances from other telomeres [50]. The protosilencer Sil2126 depends on Rap1 and the SIR complex.

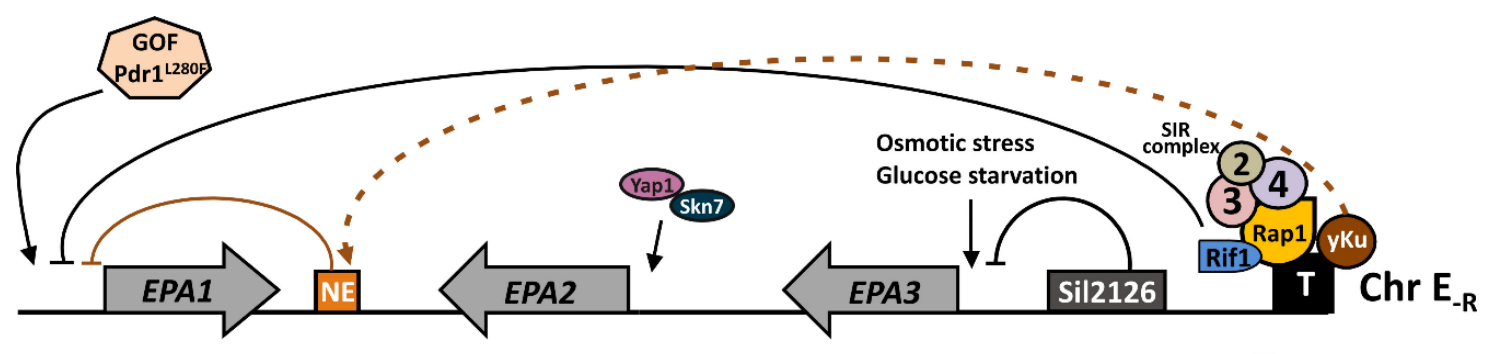

Silencing

Figure 1. Map of the right subtelomeric region of chromosome $\mathrm{E}\left(\mathrm{E}_{-\mathrm{R}}\right)$ where the EPA1, EPA2, and EPA3 cluster is localized. EPA1 expression is negatively regulated by the cis-acting element called Negative Element (NE, orange rectangle) shown as an orange T arrow, which depends on yKu70 and yKu80 proteins ( $\mathrm{yKu}$, brown circle). The dashed orange arrow indicates the genetic requirement of yKu for the activity of NE. EPA2 is induced under oxidative stress and requires Yap1 (purple) and Skn7 (dark blue) transcription factors. EPA3 is repressed by the protosilencer Sil2126 (dark gray rectangle), indicated by the black T arrow from Sil2126 to EPA3 promoter. EPA1, EPA2, and EPA3 are subject to another layer of global regulation called subtelomeric silencing (indicated by a horizontal black triangle below the chromosome and a black $\mathrm{T}$ arrow from the telomere to EPA1p). Silencing propagates from the telomere (T) and depends on the SIR complex (Sir2, Sir3, and Sir4) (2,3, and 4), Rap1 (yellow circle), Rif1 (blue), and $\mathrm{yKu}$ proteins. EPA3 expression responds also to osmotic stress and glucose starvation. 
A
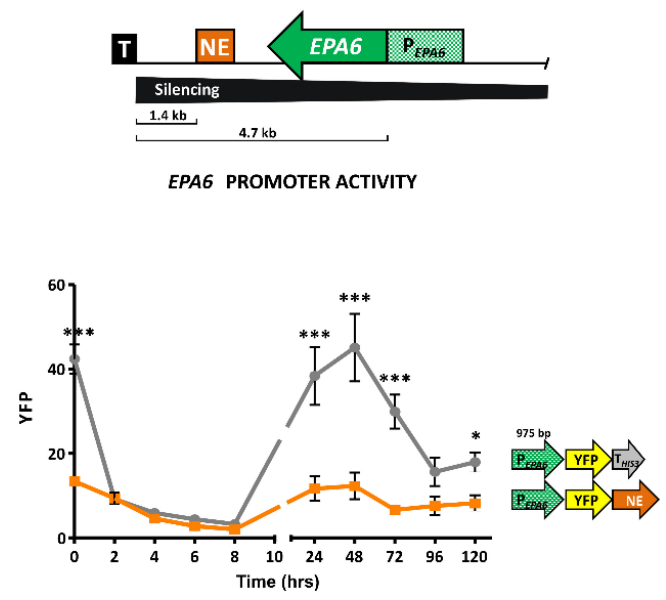

B
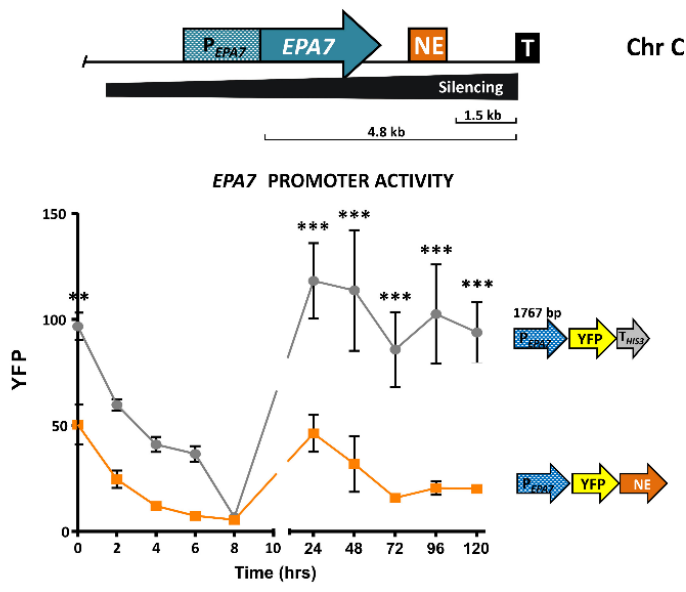

Figure 2. EPA6 and EPA7 promoters are negatively regulated by their respective negative elements (NEs). (A top) Schematic representation of the subtelomeric EPA6 gene and its downstream NE. EPA6 is repressed by subtelomeric silencing (indicated by a black horizontal triangle). (A bottom) Activity of the promoter of EPA6 is negatively regulated by its NE. (B top) Schematic representation of the subtelomeric EPA7 gene and its downstream NE. EPA7 is repressed by subtelomeric silencing (indicated by a black horizontal triangle). (B bottom) Activity of the promoter of EPA7 is negatively regulated by its NE. Replicative plasmids containing EPA6 or EPA7 promoter fused with YFP were transformed into Candida glabrata wild-type strain. One plasmid contained a heterologous $3^{\prime}$ UTR from the HIS3 gene. A second plasmid contained the cognate EPA6 or EPA7 $3^{\prime}$ UTR containing its NE. Stationary phase cultures of each of these strains were diluted into fresh rich media and fluorescence was measured by FACS every two hours. Results are the mean of three biological repetitions. Statistical analysis was performed using 2 way ANOVA Bonferroni posttests. ${ }^{*}$ means $p<0.05{ }^{* *} p<0.01$ and ${ }^{* * *} p<0.001$.

\subsection{EPA1 Is Regulated by the Transcription Factor Pdr1}

In the majority of the $C$. glabrata clinical isolates studied, Epa1 is the major adhesin conferring the ability to adhere to host cells in vitro and in vivo $[9,11,12,41]$. As described above, the transcriptional regulation of the EPA1 gene is very complex [49-53]. More recent studies, using numerous different clinical isolates, some of which are isogenic strains isolated sequentially from the same patients after treatment with antifungal drugs (azoles/fluconazole), have revealed a very interesting connection between antifungal resistance and adherence with increased virulence.

C. glabrata has unusually high rate of acquired resistance to azoles [51-53], and the major mechanism is through the induction of ABC-drug efflux pumps, especially Cdr1 and Pdh1. The regulation of transcription of these efflux pumps in C. glabrata requires the transcriptional activator Pdr1 [54,55]. Pdr1 needs to be activated by direct binding of xenobiotics such as fluconazole [56]. One of the most frequent mutations encountered in fluconazole resistant C. glabrata isolates or laboratory strains are gain of function mutations (GOF) in Pdr1. These mutant Pdr1 alleles do not require activation by fluconazole to induce transcription of not only efflux pumps, but also an array of stress response genes as well as genes involved in fatty acid metabolism, transcriptional regulation, and importantly, adhesion. Together these genes conform the pleiotropic drug resistance (PDR) network [41,53,54,57,58].

Analysis of two sequential (and related) clinical isolates taken 50 days apart from the same patient and after fluconazole treatment, led to the identification of a Pdr1 GOF allele (Pdr1 ${ }^{\mathrm{L} 280 \mathrm{~F}}$ ). By using isogenic strains carrying the wild-type Pdr1 allele or the GOF Pdr1 ${ }^{\mathrm{L} 280 \mathrm{~F}}$ it was demonstrated that this GOF allele confers resistance to fluconazole as well as increased adherence to epithelial cells. Furthermore, it was also found that the Pdr1 ${ }^{\mathrm{L} 280 \mathrm{~F}}$ allele resulted in diminished adhesion to, and uptake by, macrophages, although in a strain-specific manner [41]. Instead, the increased adherence to 
epithelial cells did not depend on the strain background. The GOF Pdr1 ${ }^{\mathrm{L} 280 \mathrm{~F}}$ allele led to an increased expression of EPA1 mRNA and higher levels of adherence to epithelial cells. Indeed, other GOF alleles in Pdr1 also led to increased EPA1 mRNA transcription and adherence, and these phenotypes are dependent on Epa1 [42].

\section{Large Variability in the Pattern of Proteins Present at the Cell Wall among C. glabrata Clinical Isolates}

\subsection{Different C. glabrata Clinical Isolates Display a Unique Pattern of Proteins at the Cell Surface}

Although several fluconazole resistant C. glabrata clinical isolates carrying GOF alleles in Pdr1 display Epa1-dependent increased adherence to epithelial cells, there are some notable exceptions like the clinical isolate DSY562. This isolate displays high levels of adherence to epithelial cells even though EPA1 mRNA levels were very low compared to other clinical isolates [42]. Genome sequencing of DSY562 and its fluconazole resistant derivative carrying Pdr1 ${ }^{\mathrm{L} 280 \mathrm{~F}}$, allowed comparisons with the CBS138 genomic sequence. These studies demonstrated that while the two related DSY clinical isolates are very similar to each other, there are several major rearrangements when they are compared to CBS138. Most of the rearrangements involve CWP-encoding genes. It is tempting to speculate that under certain in vivo conditions nonallelic homologous recombination could be induced, and/or a DNA repair mechanism might be compromised.

Genome sequencing and transcriptomic analysis of a different azole resistant clinical isolate (FFUL887) also showed that most of the genomic variation between this isolate and the CBS138 strain was found in CWP-encoding genes, especially in PWP4, PWP5, and EPA8. In addition, this study also showed that the expression of different adhesin-encoding genes varies with different Pdr1 GOF alleles [53]. Analysis of 4 pairs of clinical isolates, which were collected before and after azole treatment, led to the description of a set of Pdr1 GOF alleles conferring resistance to fluconazole but with a different impact on adherence to epithelial cells. In addition, the increased adherence was shown to be Epa1 dependent [9].

In another study, stationary phase cultures of two hyperadherent $C$. glabrata clinical isolates (PEU382 and PEU427) showed that EPA and AWP genes were not overexpressed compared to the CBS138 strain. The proteomic analysis led to the identification of 6 novel adhesins (Awp8-Awp13). These results show that there is a positive correlation between increased ability to adhere and incorporation of several adhesins at the cell wall [8].

C. glabrata is unique in that almost each clinical isolate analyzed has a different pattern of cell wall proteins present at the surface of the cell. In many cases, hyperadherent clinical isolates display overexpression of EPA1. However, there are other cases, like the ones described above, in which other adhesins at the cell wall could account for the high levels of adherence to host cells and plastic surfaces independently of Epa1. This could be advantageous since variants of the same initial strain will have different abilities to adhere to different surfaces during an infection where conditions could vary significantly and very rapidly.

In this regard, it is very interesting to point out that in some parasites like Trypanosoma brucei and Plasmodium falciparum as well as in another fungus (Pneumocystis carinii), families of adhesin-encoding genes that mediate cytoadhesion are localized at subtelomeric regions, and only one or very few of these genes are expressed at any given time. This facilitates the evasion of the immune system and allows for expansion of the adhesin-encoding gene family through nonallelic homologous recombination $[36,59]$.

\subsection{C. glabrata Shows Large Genomic Variability Involving CWP-Encoding Genes}

The first report documenting large chromosomal rearrangements showed that there were many karyotypic changes among clinical isolates analyzed and some correlated with the appearance of resistance to fluconazole after clinical treatment [60]. More recent data indicates that indeed most of C. glabrata isolates from different sources display high genetic diversity $[7,10]$. This plasticity is clearly 
seen in adhesin-like encoding genes where more than $40 \%$ of these genes are deleted or duplicated [7]. For example, the subtelomeric EPA genes show increased copy number variation due to frequent duplication events. This was determined after sequencing sequential clinical isolates where EPA2, EPA6, EPA8, EPA12, EPA22, and some members of the AWP and PWP families were duplicated [10].

A systematic study of different CBS138 strains from different laboratories, has also shown large genomic rearrangements even under laboratory conditions where the cells are grown under non-stressful conditions [61]. Analysis of the regions of the genome where most of the rearrangements occurred showed that most of them were in CWP-encoding genes that contain tandem arrays of internal repeats. It is worth noting that some of the CBS138 laboratory strains showed differential expression of adhesins of the EPA and AWP families.

Lastly, the genomic sequence of an industrial strain of C. glabrata (CCTCC M202019) for pyruvate production showed that while its genome is very similar in general to that of the CBS138 strain, there were large differences in genes that are related to carbon metabolism and pyruvate secretion. Notoriously, CWP-encoding genes were also highly variable. The genomic analysis predicted 49 genes encoding typical adhesin-like genes of which only 6 were conserved between the industrial strain and CBS138. The other adhesin-like genes displayed variations in the number of the serine and threonine-rich repeats, of which deletions were the most common. The authors also showed that this industrial strain is less adherent to endothelial cells in vitro [62].

In summary, these studies highlight the great genomic variability between different $C$. glabrata isolates with regard to the adhesins expressed at the cell surface and the large tolerance that $C$. glabrata displays to these gross rearrangements. It is not known whether the rearrangements and mutations that lead to genomic plasticity are stochastic or induced by environmental cues. It is possible that the efficient generation of genomic variability has been selected as a pathway to respond to harsh conditions to acquire traits that confer increased adherence to a variety of cells and surfaces, increased resistance to the presence of xenobiotics and/or to evade the immune system $[12,63]$. Indeed the genomic plasticity that results in a wide variety of gene expression patterns probably insures the success of $C$. glabrata as a pathogen. This raises the issue that generalizations about the behavior of C. glabrata, cannot be made based in only one strain.

\section{Role of Epa1 in Host Cell Recognition of C. glabrata}

Interactions with Cells from the Immune System: Neutrophils, Macrophages, Monocytes, Natural Killers (NK), and Dendritic Cells

Cells of the innate immune system, such as natural killers (NK), neutrophils, macrophages (derived from monocytes), and dendritic cells are the first line of defense against Candida infections. C. glabrata has evolved mechanisms that allow it to survive the attack of macrophages, and even replicate within them $[64,65]$. For phagocytosis to occur, C. glabrata must make an initial contact with the phagocytic cell. This contact is mediated by surface receptors in the immune cells and recognition molecules exposed on the cell wall of the fungus. Immune cells have pattern-recognition receptors (PRR), such as Toll-like receptors (TLRs), Dectin receptors (CLR) Dectin-1 and Dectin-2, mannose receptor (MR), and galectin-3, among others (Table 1) [66]. On the fungal side of this interaction, the cell wall of $C$. glabrata is a complex structure composed of two layers. The inner layer is a network of carbohydrates ( $\beta 1,3$ and $\beta 1,6-$ glucans and chitin) and the outer layer is constituted mainly of glycosylated mannoproteins, which are covalently bound to the inner layer glucans [67]. Adhesins in C. glabrata form part of the mannoproteins at the cell wall. The CLR receptors Dectin-1 and Dectin-2 recognize $\beta$-glucans and mannans on the surface of the fungus and in this way trigger the immune response against Candida. Dectin- 1 binds $\beta$-glucans inducing phagocytosis and the respiratory burst [68], release of neutrophil extracellular traps or NETs [69], and cytokine production [70]. Dectin-2 was first described to specifically recognize mannans on the hyphae in C. albicans [71], and together with Dectin-1 triggers a Th1 response against $C$. albicans [72]. However, in a later study using Dectin- $2^{-/-}$knockout mice, it was shown that neutrophils from these mice were less efficient at 
internalizing C. glabrata cells and triggered a weaker oxidative burst than neutrophils from wild type mice. This indicated that Dectin-2 receptors are important for $C$. glabrata recognition and not just for C. albicans hyphae recognition [73].

The interaction between Dectin- 1 and $\beta$-glucans determines $C$. glabrata colonization in a murine model of infection and importantly, the degree of $\beta$-glucans exposure at the cell surface is directly related with the fitness of $C$. glabrata in the gastrointestinal tract [74]. Thus, Dectin-1 plays a predominant role in the response against $C$. glabrata while Dectin-2 depends strongly on the fungal burden [75]. However, the specific ligand on C. glabrata recognized by Dectin receptors has not been identified yet.

It has been shown that Epa1 mediates interaction between C. glabrata and human macrophages. Heterologously expressed CgEPA1 in the nonadherent $S$. cerevisiae resulted in adherence of S. cerevisiae-pEPA1 to human derived macrophages. Adherence is followed by phagocytosis and cytokine release (IL-8 and TNF- $\alpha$ ), however, C. glabrata cells expressing EPA1 adhere efficiently to human macrophages but phagocytosis and cytokine release are inhibited. It is important to point out that Epa1 expressed in S. cerevisiae can also mediate adherence to murine derived macrophages, but only after Dectin-1 receptors have been blocked. This highlights the important differences between murine and human derived macrophages [17].

Table 1. Summary of the types of cells to which Candida glabrata can adhere in vitro and in vivo, the receptors in host cells, microorganisms, or substrates involved in the interaction, and the ligand on C. glabrata recognized by the receptor.

\begin{tabular}{|c|c|c|c|c|}
\hline \multicolumn{2}{|r|}{ Interaction with } & \multirow{2}{*}{$\begin{array}{l}\text { Receptor in the Host or } \\
\text { Microorganism }\end{array}$} & \multirow{2}{*}{ 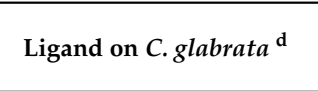 } & \multirow{2}{*}{ Reference } \\
\hline Type of Cells & Specific Cell Line ${ }^{a}$ & & & \\
\hline \multirow{7}{*}{ Epithelial cells } & HEp2 (human), CHO-Lec2 (hamster) & $\mathrm{ND}^{\mathrm{c}}$ & Epa1 & [11] \\
\hline & Cardiac endothelium (guinea pig) & ND & ND & {$[15]$} \\
\hline & Caco-2 (human) & ND & Epa1 & [29] \\
\hline & Lec2 (hamster) & ND & Epa6, Ера7 & [33] \\
\hline & OKF6/TERT-2 (human) & ND & $\beta$-glucan & {$[76]$} \\
\hline & UVECS (human) & ND & Pwp7, Aed1 & {$[14]$} \\
\hline & OKF6/TERT-2 (human) & CDw17 & ND & {$[77]$} \\
\hline \multirow{5}{*}{ Immune cells } & Natural Killers (NK) & $\begin{array}{l}\text { Nkp46 (human) } \\
\text { NCR1 (murine) }\end{array}$ & Epa1, Epa6, Epa7 & [18] \\
\hline & Macrophages (human/murine) & Dectin1, Dectin2 & $\beta$-glucan & [73-75] \\
\hline & Macropnages (numan/murine) & ND & Epa1 & [17] \\
\hline & Dendritic Cells (murine) & ND & Epa1/ND & {$[16,17]$} \\
\hline & Neutrophils (murine) & Dectin2 & $\beta$-glucan & {$[73]$} \\
\hline $\begin{array}{l}\text { Platelets } \\
\text { (murine) }\end{array}$ & & ND & ND & [78] \\
\hline \multirow{2}{*}{ Candida spp. } & C. albicans (hyphae) & Hwp1, Als3, Als1 & $\begin{array}{c}\text { Epa8, Epa19, Awp2, Awp7, } \\
\text { CAGL0F00181 }\end{array}$ & [79] \\
\hline & C. krusei & ND & ND & {$[80,81]$} \\
\hline \multirow{3}{*}{ Others } & Fibronectin & & Epa6 & [82] \\
\hline & Osteoblast (human) & ND & ND & {$[83]$} \\
\hline & S. marscesens, P. aeruginosa, A. fumigatus & $\mathrm{NI}{ }^{\mathrm{e}}$ & NI & [84-86] \\
\hline
\end{tabular}

\footnotetext{
${ }^{\text {a }}$ Name of the cell lines or types of immune cells used to determine adherence. Abbreviations mean: HEp2 = Human Epidermoid cancer cells. $\mathrm{CHO}=$ Chinese Hamster Ovary. Lec2 $=\mathrm{CHO}$ derived mutants in CMP-syalic acid translocation. Caco-2 $=$ adeno Carcinoma of the colon. OKF6/TERT-2 $=$ human Oral Keratinocytes expressing hTERT subunit. UVEC = Umbilical Vein Endothelial Cells. The origin of the cell type (human or murine) is indicated in parenthesis. ${ }^{b}$ Receptor identified on the surface of the cell to which C. glabrata adheres. ${ }^{\mathrm{c}}$ ND means not determined. ${ }^{\mathrm{d}}$ Ligand identified on C. glabrata that is recognized by the receptor. ${ }^{\mathrm{e}} \mathrm{NI}$ means not investigated.
}

NK cells are a different type of lymphocytic cell from the innate immune system that can recognize cells that have been infected by viruses, bacteria, or tumoral cells through different cell surface receptors. NK cells are important to fight fungal infections. Human NK cells are capable of recognizing C. glabrata cells through the NKp46 receptor and also by murine NK cells through the orthologous murine receptor NCR1. The NKp46 receptor specifically recognizes Epa1, Epa6, and Epa7. Clearance of C. glabrata systemic infections in mice depends on the presence of these adhesins and the NCR1 receptor on the murine NK cells [18]. It is proposed that NKp46/NCR1 may be a new type of PRR in which the 
receptor is glycosylated with the same pattern as the host cells. C. glabrata cells then recognize the glycosylation pattern of the NKp46/NCR1 through Epa1, Epa6, and Epa7 and bind to the NK cells. In this way, C. glabrata is lured to the NK cells and killed [18].

In addition to adherence of $C$. glabrata to NK cells and macrophages, there is evidence that shows that $C$. glabrata can activate murine bone marrow-derived dendritic cells through the toll-like receptor TLR7 and resulting in the release of IFN- $\beta$. This modulates the immune response through IFNs-I signaling [16].

\section{Interactions with Other Microorganisms}

In addition to $C$. glabrata interactions with host cells, it is well known that $C$. glabrata can interact efficiently with other microorganisms. Early studies found that a sizable proportion of candidemias are actually mixed infections. Up to $24 \%$ of the reviewed cases presented concomitant bacteremia and between $3 \%$ and $4 \%$ of the candidemias contained more than one Candida species. Interactions between C. glabrata with C. albicans, C. krusei, and C. tropicalis have also been detected [81]. In terms of clinical consequences, mixed infections are difficult to diagnose and treat because they sometimes need changes in treatment [81] and in some cases have been associated with higher mortality rates [87]. Initially, it was discovered that $C$. albicans requires Als1, Als3, and Als5 for cell-to-cell self-aggregation. In contrast, C. glabrata does not form aggregates. However, when C. glabrata and C. albicans are mixed, cells can aggregate suggesting that the interaction between C. albicans and C. glabrata might be important for pathogenesis of C. glabrata [88]. C. glabrata by itself is rarely found in oral candidiasis, but it is more frequently found in combination with C. albicans. In studies performed in reconstituted human oral epithelium, it was found that for C. glabrata single infections, colonization of the oral epithelium was strain dependent. However, C. albicans was able to increase invasiveness of all the C. glabrata strains tested, including those that were less efficient at colonization [89].

C. glabrata and C. albicans can form mixed biofilms because C. glabrata adheres tightly to C. albicans hyphae (not to the yeast form). C. glabrata recognizes the hypha-specific adhesins Als1 and Als3. Furthermore, heterologous expression of ALS1 and ALS3 in S. cerevisiae prompted adherence of C. glabrata to Als1 and Als3 expressing S. cerevisiae cells. Importantly, coinfection of C. albicans and C. glabrata in a mouse model of oropharyngeal infection (OPC), showed that when C. albicans is present invading the oral epithelium, it allows for colonization and invasion of C. glabrata in proportion to the level of $C$. albicans invasion [79]. In this interaction, the C. albicans adhesins Als1 and Als3 and the C. glabrata Epa8, Epa19, Awp2, and Awp7 adhesins and the CAGLOF00181g adhesin-encoding gene are thought to play an important role [79]. Consistently, with the differential expression of adhesin-encoding genes discussed in this review, different $C$. glabrata strains displayed different levels of adherence to C. albicans hyphae [79].

C. albicans and C. glabrata mixed infections are also commonly found in vaginal infections. In a study using reconstituted human vaginal epithelium, it was found that even though C. glabrata alone can colonize the vaginal epithelium, the presence of $C$. albicans resulted in increased colonization, invasiveness, and tissue damage. This suggests that $C$. albicans could be improving the invasiveness of C. glabrata in this in vitro model [43]. Besides mixed Candida infections, there is a report of an invasive infection of C. glabrata with Aspergillus fumigatus, which was resistant to monotherapy antifungal treatment that had to be modified [85].

There are some case studies that have found mixed infections of C. glabrata and bacteria, for example C. glabrata with Serratia marcescens. This mixed infection was associated with recurrent C. glabrata infections at the particular site [86]. C. glabrata has also been found together with Pseudomonas aeruginosa, and in this case C. glabrata biofilms were inhibited by the presence of P. aeruginosa [84]. 


\section{Conclusions}

The ability to adhere to different host cell types, abiotic surfaces such as medical devices, and other microorganisms is thought to be an essential first step in Candida glabrata pathogenesis. In this regard, C. glabrata has evolved to acquire an unusually large number of genes encoding cell wall proteins (CWPs). In the pathogenic species within the Nakaseomyces genus, the appearance of the ability to colonize the mammalian host coincides with the large expansion of adhesin-like encoding gene families, specifically the EPA gene family.

An extremely relevant characteristic of $C$. glabrata is that there is a large genomic variability among clinical isolates and even between cultures of the same standard strain CBS138 from different laboratories. Importantly, the largest variation occurs within the CWP-encoding genes. This has a huge impact on the variability that can be generated in CWPs. As a consequence every strain analyzed seems to display a unique profile of cell surface proteins and this has a direct impact on the ability to adhere to different types of host cells, to abiotic surfaces, to other pathogens, or avoid the immune system.

In addition, each of these genes is tightly regulated by several layers of regulation. This in turn depends on the particular strain. Subtelomeric silencing provides a global regulatory network, but in addition there are cis-acting elements, transcriptional activators, and repressors that could be sensing nutritional signals, oxidative stress, and the presence of xenobiotics, among others.

Thus, pathogenicity and ability to adhere to many cell types, including other microorganisms and abiotic surfaces, and the ability to respond to xenobiotics are tightly correlated in C. glabrata.

Future characterization of sequential clinical isolates that include transcriptomic and proteomic analysis and correlation with clinical treatment will help understand the cues to which C. glabrata responds to in the host and how it is manifested in the cell wall composition. Another important issue to understand is whether C. glabrata has evolved to respond to stressful conditions by triggering high rates of homologous recombination. This would generate genomic variability in the population and thus insure that some individuals will survive.

A detailed understanding of the evolution of adhesin-encoding genes and the regulation of their expression is of pivotal importance to host-microbe interactions to devise novel treatments for these serious infections.

Author Contributions: I.C., E.L.-F. and G.G.-E. designed the review. I.C. wrote the review, A.D.L.P. was involved in the editing, and all authors were involved in the preparation of the submitted version of the review.

Acknowledgments: This work was supported by the bilateral grant FWO-Flanders (VS.036.14N)/CONACYTMexico (219669). E.L.-F. was a recipient of CONACYT fellowship No. 261740.

Conflicts of Interest: The authors declare no conflicts of interest.

\section{References}

1. Brown, G.D.; Denning, D.W.; Gow, N.A.; Levitz, S.M.; Netea, M.G.; White, T.C. Hidden killers: Human fungal infections. Sci. Transl. Med. 2012, 4, 165rv113. [CrossRef] [PubMed]

2. Diekema, D.; Arbefeville, S.; Boyken, L.; Kroeger, J.; Pfaller, M. The changing epidemiology of healthcareassociated candidemia over three decades. Diagn. Microbiol. Infect. Dis. 2012, 73, 45-48. [CrossRef] [PubMed]

3. Pfaller, M.A.; Andes, D.R.; Diekema, D.J.; Horn, D.L.; Reboli, A.C.; Rotstein, C.; Franks, B.; Azie, N.E. Epidemiology and outcomes of invasive candidiasis due to non-albicans species of Candida in 2,496 patients: Data from the Prospective Antifungal Therapy (PATH) registry 2004-2008. PLoS ONE 2014, 9, e101510. [CrossRef] [PubMed]

4. Guinea, J. Global trends in the distribution of Candida species causing candidemia. Clin. Microbiol. Infect. 2014, 20, 5-10. [CrossRef] [PubMed]

5. Khatib, R.; Johnson, L.B.; Fakih, M.G.; Riederer, K.; Briski, L. Current trends in candidemia and species distribution among adults: Candida glabrata surpasses C. albicans in diabetic patients and abdominal sources. Mycoses 2016, 59, 781-786. [CrossRef] [PubMed] 
6. Castanheira, M.; Messer, S.A.; Rhomberg, P.R.; Pfaller, M.A. Antifungal susceptibility patterns of a global collection of fungal isolates: Results of the SENTRY Antifungal Surveillance Program (2013). Diagn. Microbiol. Infect. Dis. 2016, 85, 200-204. [CrossRef] [PubMed]

7. Carrete, L.; Ksiezopolska, E.; Pegueroles, C.; Gomez-Molero, E.; Saus, E.; Iraola-Guzman, S.; Loska, D.; Bader, O.; Fairhead, C.; Gabaldon, T. Patterns of Genomic Variation in the Opportunistic Pathogen Candida glabrata Suggest the Existence of Mating and a Secondary Association with Humans. Curr. Biol. 2018, 28, 15-27. [CrossRef] [PubMed]

8. Gómez-Molero, E.; de Boer, A.D.; Dekker, H.L.; Moreno-Martínez, A.; Kraneveld, E.A.; Chauhan, N.; Weig, M.; de Soet, J.J.; de Koster, C.G.; Bader, O.; et al. Proteomic analysis of hyperadhesive Candida glabrata clinical isolates reveals a core wall proteome and differential incorporation of adhesins. FEMS Yeast Res. 2015, 15. [CrossRef] [PubMed]

9. Ni, Q.; Wang, C.; Tian, Y.; Dong, D.; Jiang, C.; Mao, E.; Peng, Y. CgPDR1 gain-of-function mutations lead to azole-resistance and increased adhesion in clinical Candida glabrata strains. Mycoses 2018. [CrossRef] [PubMed]

10. Vale-Silva, L.; Beaudoing, E.; Tran, V.D.T.; Sanglard, D. Comparative Genomics of Two Sequential Candida glabrata Clinical Isolates. G3 Genes Genomes Genet. 2017, 7, 2413-2426. [CrossRef] [PubMed]

11. Cormack, B.P.; Ghori, N.; Falkow, S. An adhesin of the yeast pathogen Candida glabrata mediating adherence to human epithelial cells. Science 1999, 285, 578-582. [CrossRef] [PubMed]

12. Martinez-Jimenez, V.; Ramirez-Zavaleta, C.Y.; Orta-Zavalza, E.; Diaz de Leon, G.; Gutierrez-Escobedo, G.; Ponce de Leon, A.; Sifuentes-Osornio, J.; Bobadilla Del Valle, M.; De Las Penas, A.; Castano, I. Sir3 Polymorphisms in Candida glabrata Clinical Isolates. Mycopathologia 2013, 175, 207-219. [CrossRef] [PubMed]

13. Zupancic, M.L.; Frieman, M.; Smith, D.; Alvarez, R.A.; Cummings, R.D.; Cormack, B.P. Glycan microarray analysis of Candida glabrata adhesin ligand specificity. Mol. Microbiol. 2008, 68, 547-559. [CrossRef] [PubMed]

14. Desai, C.; Mavrianos, J.; Chauhan, N. Candida glabrata Pwp7p and Aed1p are required for adherence to human endothelial cells. FEMS Yeast Res. 2011, 11, 595-601. [CrossRef] [PubMed]

15. Torres-Tirado, D.; Knabb, M.; Castano, I.; Patron-Soberano, A.; De Las Penas, A.; Rubio, R. Candida glabrata binds to glycosylated and lectinic receptors on the coronary endothelial luminal membrane and inhibits flow sense and cardiac responses to agonists. Am. J. Physiol. Regul. Integr. Comp. Physiol. 2016, 310, R24-R32. [CrossRef] [PubMed]

16. Bourgeois, C.; Majer, O.; Frohner, I.E.; Lesiak-Markowicz, I.; Hildering, K.S.; Glaser, W.; Stockinger, S.; Decker, T.; Akira, S.; Muller, M.; et al. Conventional dendritic cells mount a type I IFN response against Candida spp. requiring novel phagosomal TLR7-mediated IFN- $\beta$ signaling. J. Immunol. 2011, 186, 3104-3112. [CrossRef] [PubMed]

17. Kuhn, D.M.; Vyas, V.K. The Candida glabrata adhesin Epa1p causes adhesion, phagocytosis, and cytokine secretion by innate immune cells. FEMS Yeast Res. 2012, 12, 398-414. [CrossRef] [PubMed]

18. Vitenshtein, A.; Charpak-Amikam, Y.; Yamin, R.; Bauman, Y.; Isaacson, B.; Stein, N.; Berhani, O.; Dassa, L.; Gamliel, M.; Gur, C.; et al. NK Cell Recognition of Candida glabrata through Binding of NKp46 and NCR1 to Fungal Ligands Epa1, Epa6, and Epa7. Cell Host Microbe 2016, 20, 527-534. [CrossRef] [PubMed]

19. Santoni, G.; Birarelli, P.; Hong, L.J.; Gamero, A.; Djeu, J.Y.; Piccoli, M. An alpha 5 beta 1-like integrin receptor mediates the binding of less pathogenic Candida species to fibronectin. J. Med. Microbiol. 1995, 43, 360-367. [CrossRef] [PubMed]

20. Parnanen, P.; Kari, K.; Virtanen, I.; Sorsa, T.; Meurman, J.H. Human laminin-332 degradation by Candida proteinases. J. Oral Pathol. Med. 2008, 37, 329-335. [CrossRef] [PubMed]

21. Parnanen, P.; Meurman, J.H.; Virtanen, I. Laminin-511 and fibronectin degradation with Candida yeast. J. Oral Pathol. Med. 2009, 38, 768-772. [CrossRef] [PubMed]

22. Kojic, E.M.; Darouiche, R.O. Candida infections of medical devices. Clin. Microbiol. Rev. 2004, 17, $255-267$. [CrossRef] [PubMed]

23. Timmermans, B.; De Las Penas, A.; Castano, I.; Van Dijck, P. Adhesins in Candida glabrata. J. Fungi 2018, 4, 60. [CrossRef] [PubMed]

24. Verstrepen, K.J.; Klis, F.M. Flocculation, adhesion and biofilm formation in yeasts. Mol. Microbiol. 2006, 60, 5-15. [CrossRef] [PubMed] 
25. De Groot, P.W.J.; Kraneveld, E.A.; Yin, Q.Y.; Dekker, H.L.; Gross, U.; Crielaard, W.; de Koster, C.G.; Bader, O.; Klis, F.M.; Weig, M. The Cell Wall of the Human Pathogen Candida glabrata: Differential Incorporation of Novel Adhesin-Like Wall Proteins. Eukaryot. Cell 2008, 7, 1951-1964. [CrossRef] [PubMed]

26. Weig, M.; Jansch, L.; Gross, U.; De Koster, C.G.; Klis, F.M.; De Groot, P.W.J. Systematic identification in silico of covalently bound cell wall proteins and analysis of protein-polysaccharide linkages of the human pathogen Candida glabrata. Microbiology 2004, 150, 3129-3144. [CrossRef] [PubMed]

27. Kapteyn, J.C.; Van Den Ende, H.; Klis, F.M. The contribution of cell wall proteins to the organization of the yeast cell wall. Biochim. Biophys. Acta Gen. Subj. 1999, 1426, 373-383. [CrossRef]

28. De Groot, P.W.; Bader, O.; de Boer, A.D.; Weig, M.; Chauhan, N. Adhesins in human fungal pathogens: Glue with plenty of stick. Eukaryot. Cell 2013, 12, 470-481. [CrossRef] [PubMed]

29. Maestre-Reyna, M.; Diderrich, R.; Veelders, M.S.; Eulenburg, G.; Kalugin, V.; Bruckner, S.; Keller, P.; Rupp, S.; Mosch, H.U.; Essen, L.O. Structural basis for promiscuity and specificity during Candida glabrata invasion of host epithelia. Proc. Natl. Acad. Sci. USA 2012, 109, 16864-16869. [CrossRef] [PubMed]

30. Xie, X.; Lipke, P.N. On the evolution of fungal and yeast cell walls. Yeast 2010, 8, 479-488. [CrossRef] [PubMed]

31. Dujon, B.; Sherman, D.; Fischer, G.; Durrens, P.; Casaregola, S.; Lafontaine, I.; De Montigny, J.; Marck, C.; Neuveglise, C.; Talla, E.; et al. Genome evolution in yeasts. Nature 2004, 430, 35-44. [CrossRef] [PubMed]

32. Gabaldon, T.; Martin, T.; Marcet-Houben, M.; Durrens, P.; Bolotin-Fukuhara, M.; Lespinet, O.; Arnaise, S.; Boisnard, S.; Aguileta, G.; Atanasova, R.; et al. Comparative genomics of emerging pathogens in the Candida glabrata clade. BMC Genom. 2013, 14, 623. [CrossRef] [PubMed]

33. De Las Penas, A.; Pan, S.J.; Castano, I.; Alder, J.; Cregg, R.; Cormack, B.P. Virulence-related surface glycoproteins in the yeast pathogen Candida glabrata are encoded in subtelomeric clusters and subject to RAP1- and SIR-dependent transcriptional silencing. Genes Dev. 2003, 17, 2245-2258. [CrossRef] [PubMed]

34. Castano, I.; Pan, S.J.; Zupancic, M.; Hennequin, C.; Dujon, B.; Cormack, B.P. Telomere length control and transcriptional regulation of subtelomeric adhesins in Candida glabrata. Mol. Microbiol. 2005, 55, 1246-1258. [CrossRef] [PubMed]

35. Gabaldon, T.; Carrete, L. The birth of a deadly yeast: Tracing the evolutionary emergence of virulence traits in Candida glabrata. FEMS Yeast Res. 2016, 16, fov110. [CrossRef] [PubMed]

36. Vestrepen, K.; Fink, G.R. Genetic and epigenetic mechanisms underlying cell-surface variability in protozoa and fungi. Annu. Rev. Genet. 2009, 43, 1-24. [CrossRef] [PubMed]

37. Kaur, R.; Domergue, R.; Zupancic, M.L.; Cormack, B.P. A yeast by any other name: Candida glabrata and its interaction with the host. Curr. Opin. Microbiol. 2005, 8, 378-384. [CrossRef] [PubMed]

38. Kraneveld, E.A.; de Soet, J.J.; Deng, D.M.; Dekker, H.L.; de Koster, C.G.; Klis, F.M.; Crielaard, W.; de Groot, P.W.J. Identification and Differential Gene Expression of Adhesin-Like Wall Proteins in Candida glabrata Biofilms. Mycopathologia 2011, 172, 415-427. [CrossRef] [PubMed]

39. Thierry, A.; Bouchier, C.; Dujon, B.; Richard, G.F. Megasatellites: A peculiar class of giant minisatellites in genes involved in cell adhesion and pathogenicity in Candida glabrata. Nucleic Acids Res. 2008, 36, 5970-5982. [CrossRef] [PubMed]

40. Verstrepen, K.J.; Jansen, A.; Lewitter, F.; Fink, G.R. Intragenic tandem repeats generate functional variability. Nat. Genet. 2005, 37, 986-990. [CrossRef] [PubMed]

41. Vale-Silva, L.; Ischer, F.; Leibundgut-Landmann, S.; Sanglard, D. Gain-of-function mutations in PDR1, a regulator of antifungal drug resistance in Candida glabrata, control adherence to host cells. Infect. Immun. 2013, 81, 1709-1720. [CrossRef] [PubMed]

42. Vale-Silva, L.A.; Moeckli, B.; Torelli, R.; Posteraro, B.; Sanguinetti, M.; Sanglard, D. Upregulation of the Adhesin Gene EPA1 Mediated by PDR1 in Candida glabrata Leads to Enhanced Host Colonization. mSphere 2016, 1. [CrossRef] [PubMed]

43. Alves, C.T.; Wei, X.Q.; Silva, S.; Azeredo, J.; Henriques, M.; Williams, D.W. Candida albicans promotes invasion and colonisation of Candida glabrata in a reconstituted human vaginal epithelium. J. Infect. 2014, 69, 396-407. [CrossRef] [PubMed]

44. Domergue, R.; Castano, I.; De Las Penas, A.; Zupancic, M.; Lockatell, V.; Hebel, J.R.; Johnson, D.; Cormack, B.P. Nicotinic acid limitation regulates silencing of Candida adhesins during UTI. Science 2005, 308, 866-870. [CrossRef] [PubMed] 
45. De Las Penas, A.; Juarez-Cepeda, J.; Lopez-Fuentes, E.; Briones-Martin-Del-Campo, M.; Gutierrez-Escobedo, G.; Castano, I. Local and regional chromatin silencing in Candida glabrata: Consequences for adhesion and the response to stress. FEMS Yeast Res. 2015, 15, fov056. [CrossRef] [PubMed]

46. Rosas-Hernandez, L.L.; Juarez-Reyes, A.; Arroyo-Helguera, O.E.; De Las Penas, A.; Pan, S.J.; Cormack, B.P.; Castano, I. yKu70/yKu80 and Rif1 Regulate Silencing Differentially at Telomeres in Candida glabrata. Eukaryot. Cell 2008, 7, 2168-2178. [CrossRef] [PubMed]

47. Juarez-Cepeda, J.; Orta-Zavalza, E.; Canas-Villamar, I.; Arreola-Gomez, J.; Perez-Cornejo, G.P.; Hernandez-Carballo, C.Y.; Gutierrez-Escobedo, G.; Castano, I.; De Las Penas, A. The Epa2 adhesin encoding gene is responsive to oxidative stress in the opportunistic fungal pathogen Candida glabrata. Curr. Genet. 2015, 61, 529-544. [CrossRef] [PubMed]

48. Roetzer, A.; Gregori, C.; Jennings, A.M.; Quintin, J.; Ferrandon, D.; Butler, G.; Kuchler, K.; Ammerer, G.; Schuller, C. Candida glabrata environmental stress response involves Saccharomyces cerevisiae Msn2/4 orthologous transcription factors. Mol. Microbiol. 2008, 69, 603-620. [CrossRef] [PubMed]

49. Gallegos-Garcia, V.; Pan, S.J.; Juarez-Cepeda, J.; Ramirez-Zavaleta, C.Y.; Martin-del-Campo, M.B.; Martinez-Jimenez, V.; Castano, I.; Cormack, B.; De Las Penas, A. A novel downstream regulatory element cooperates with the silencing machinery to repress EPA1 expression in Candida glabrata. Genetics 2012, 190, 1285-1297. [CrossRef] [PubMed]

50. Juarez-Reyes, A.; Ramirez-Zavaleta, C.Y.; Medina-Sanchez, L.; De Las Penas, A.; Castano, I. A Protosilencer of subtelomeric gene expression in Candida glabrata with unique properties. Genetics 2012, 190, 101-111. [CrossRef] [PubMed]

51. Pfaller, M.A.; Messer, S.A.; Boyken, L.; Tendolkar, S.; Hollis, R.J.; Diekema, D.J. Variation in susceptibility of bloodstream isolates of Candida glabrata to fluconazole according to patient age and geographic location. J. Clin. Microbiol. 2003, 41, 2176-2179. [CrossRef] [PubMed]

52. Pfaller, M.A.; Messer, S.A.; Hollis, R.J.; Boyken, L.; Tendolkar, S.; Kroeger, J.; Diekema, D.J. Variation in susceptibility of bloodstream isolates of Candida glabrata to fluconazole according to patient age and geographic location in the United States in 2001 to 2007. J. Clin. Microbiol. 2009, 47, 3185-3190. [CrossRef] [PubMed]

53. Salazar, S.B.; Wang, C.; Munsterkotter, M.; Okamoto, M.; Takahashi-Nakaguchi, A.; Chibana, H.; Lopes, M.M.; Guldener, U.; Butler, G.; Mira, N.P. Comparative genomic and transcriptomic analyses unveil novel features of azole resistance and adaptation to the human host in Candida glabrata. FEMS Yeast Res. 2018, 18, fox079. [CrossRef] [PubMed]

54. Vermitsky, J.P.; Earhart, K.D.; Smith, W.L.; Homayouni, R.; Edlind, T.D.; Rogers, P.D. Pdr1 regulates multidrug resistance in Candida glabrata: Gene disruption and genome-wide expression studies. Mol. Microbiol. 2006, 61, 704-722. [CrossRef] [PubMed]

55. Vermitsky, J.P.; Edlind, T.D. Azole resistance in Candida glabrata: Coordinate upregulation of multidrug transporters and evidence for a Pdr1-like transcription factor. Antimicrob. Agents Chemother. 2004, 48, 3773-3781. [CrossRef] [PubMed]

56. Thakur, J.K.; Arthanari, H.; Yang, F.J.; Pan, S.J.; Fan, X.C.; Breger, J.; Frueh, D.P.; Gulshan, K.; Li, D.K.; Mylonakis, E.; et al. A nuclear receptor-like pathway regulating multidrug resistance in fungi. Nature 2008, 452, 604. [CrossRef] [PubMed]

57. Ferrari, S.; Ischer, F.; Calabrese, D.; Posteraro, B.; Sanguinetti, M.; Fadda, G.; Rohde, B.; Bauser, C.; Bader, O.; Sanglard, D. Gain of Function Mutations in CgPDR1 of Candida glabrata Not Only Mediate Antifungal Resistance but Also Enhance Virulence. PLoS Pathog. 2009, 5, e1000268. [CrossRef] [PubMed]

58. Sanguinetti, M.; Posteraro, B.; Fiori, B.; Ranno, S.; Torelli, R.; Fadda, G. Mechanisms of azole resistance in clinical isolates of Candida glabrata collected during a hospital survey of antifungal resistance. Antimicrob. Agents Chemother. 2005, 49, 668-679. [CrossRef] [PubMed]

59. Ottaviani, A.; Gilson, E.; Magdinier, F. Telomeric position effect: From the yeast paradigm to human pathologies? Biochimie 2008, 90, 93-107. [CrossRef] [PubMed]

60. Polakova, S.; Blume, C.; Zarate, J.A.; Mentel, M.; Jorck-Ramberg, D.; Stenderup, J.; Piskur, J. Formation of new chromosomes as a virulence mechanism in yeast Candida glabrata. Proc. Natl. Acad. Sci. USA 2009, 106, 2688-2693. [CrossRef] [PubMed] 
61. Bader, O.; Schwarz, A.; Kraneveld, E.A.; Tangwattanachuleeporn, M.; Schmidt, P.; Jacobsen, M.D.; Gross, U.; De Groot, P.W.; Weig, M. Gross karyotypic and phenotypic alterations among different progenies of the Candida glabrata CBS138/ATCC2001 reference strain. PLoS ONE 2012, 7, e52218. [CrossRef] [PubMed]

62. Xu, N.; Ye, C.; Chen, X.; Liu, J.; Liu, L.; Chen, J. Genome Sequencing of the Pyruvate-producing Strain Candida glabrata CCTCC M202019 and Genomic Comparison with Strain CBS138. Sci. Rep. 2016, 6, 34893. [CrossRef] [PubMed]

63. Cuellar-Cruz, M.; Castano, I.; Arroyo-Helguera, O.; De Las Penas, A. Oxidative stress response to menadione and cumene hydroperoxide in the opportunistic fungal pathogen Candida glabrata. Mem. Inst. Oswaldo Cruz 2009, 104, 649-654. [CrossRef] [PubMed]

64. Kaur, R.; Ma, B.; Cormack, B.P. A family of glycosylphosphatidylinositol-linked aspartyl proteases is required for virulence of Candida glabrata. Proc. Natl. Acad. Sci. USA 2007, 104, 7628-7633. [CrossRef] [PubMed]

65. Seider, K.; Brunke, S.; Schild, L.; Jablonowski, N.; Wilson, D.; Majer, O.; Barz, D.; Haas, A.; Kuchler, K.; Schaller, M.; et al. The facultative intracellular pathogen Candida glabrata subverts macrophage cytokine production and phagolysosome maturation. J. Immunol. 2011, 187, 3072-3086. [CrossRef] [PubMed]

66. Netea, M.G.; Joosten, L.A.; van der Meer, J.W.; Kullberg, B.J.; van de Veerdonk, F.L. Immune defence against Candida fungal infections. Nat. Rev. Immunol. 2015, 15, 630-642. [CrossRef] [PubMed]

67. Lipke, P.; Ovalle, R. Cell wall architecture in yeast: New structure and new challenges. J. Bacteriol. 1998, 180, 3735-3740. [PubMed]

68. Goodridge, H.S.; Reyes, C.N.; Becker, C.A.; Katsumoto, T.R.; Ma, J.; Wolf, A.J.; Bose, N.; Chan, A.S.; Magee, A.S.; Danielson, M.E.; et al. Activation of the innate immune receptor Dectin-1 upon formation of a 'phagocytic synapse'. Nature 2011, 472, 471-475. [CrossRef] [PubMed]

69. Branzk, N.; Lubojemska, A.; Hardison, S.E.; Wang, Q.; Gutierrez, M.G.; Brown, G.D.; Papayannopoulos, V. Neutrophils sense microbe size and selectively release neutrophil extracellular traps in response to large pathogens. Nat. Immunol. 2014, 15, 1017-1025. [CrossRef] [PubMed]

70. Xu, S.; Huo, J.; Lee, K.G.; Kurosaki, T.; Lam, K.P. Phospholipase Cgamma2 is critical for Dectin-1-mediated $\mathrm{Ca}^{2+}$ flux and cytokine production in dendritic cells. J. Biol. Chem. 2009, 284, 7038-7046. [CrossRef] [PubMed]

71. McGreal, E.P.; Rosas, M.; Brown, G.D.; Zamze, S.; Wong, S.Y.; Gordon, S.; Martinez-Pomares, L.; Taylor, P.R. The carbohydrate-recognition domain of Dectin-2 is a C-type lectin with specificity for high mannose. Glycobiology 2006, 16, 422-430. [CrossRef] [PubMed]

72. Sato, K.; Yang, X.L.; Yudate, T.; Chung, J.S.; Wu, J.; Luby-Phelps, K.; Kimberly, R.P.; Underhill, D.; Cruz, P.D., Jr.; Ariizumi, K. Dectin-2 is a pattern recognition receptor for fungi that couples with the FC receptor gamma chain to induce innate immune responses. J. Biol. Chem. 2006, 281, 38854-38866. [CrossRef] [PubMed]

73. Ifrim, D.C.; Bain, J.M.; Reid, D.M.; Oosting, M.; Verschueren, I.; Gow, N.A.; van Krieken, J.H.; Brown, G.D.; Kullberg, B.J.; Joosten, L.A.; et al. Role of Dectin-2 for host defense against systemic infection with Candida glabrata. Infect. Immun. 2014, 82, 1064-1073. [CrossRef] [PubMed]

74. Sem, X.; Le, G.T.; Tan, A.S.; Tso, G.; Yurieva, M.; Liao, W.W.; Lum, J.; Srinivasan, K.G.; Poidinger, M.; Zolezzi, F.; et al. Beta-glucan Exposure on the Fungal Cell Wall Tightly Correlates with Competitive Fitness of Candida Species in the Mouse Gastrointestinal Tract. Front. Cell. Infect. Microbiol. 2016, 6, 186. [CrossRef] [PubMed]

75. Chen, S.M.; Shen, H.; Zhang, T.; Huang, X.; Liu, X.Q.; Guo, S.Y.; Zhao, J.J.; Wang, C.F.; Yan, L.; Xu, G.T.; et al. Dectin-1 plays an important role in host defense against systemic Candida glabrata infection. Virulence 2017, 8, 1643-1656. [CrossRef] [PubMed]

76. Swidergall, M.; Solis, N.V.; Lionakis, M.S.; Filler, S.G. EphA2 is an epithelial cell pattern recognition receptor for fungal beta-glucans. Nat. Microbiol. 2018, 3, 53-61. [CrossRef] [PubMed]

77. Li, L.; Dongari-Bagtzoglou, A. Epithelial GM-CSF induction by Candida glabrata. J. Dent. Res. 2009, 88, 746-751. [CrossRef] [PubMed]

78. Robert, R.; Nail, S.; Marot-Leblond, A.; Cottin, J.; Miegeville, M.; Quenouillere, S.; Mahaza, C.; Senet, J.M. Adherence of platelets to Candida species in vivo. Infect. Immun. 2000, 68, 570-576. [CrossRef] [PubMed]

79. Tati, S.; Davidow, P.; McCall, A.; Hwang-Wong, E.; Rojas, I.G.; Cormack, B.; Edgerton, M. Candida glabrata Binding to Candida albicans Hyphae Enables Its Development in Oropharyngeal Candidiasis. PLoS Pathog. 2016, 12, e1005522. [CrossRef] [PubMed] 
80. Rossoni, R.D.; Barros, P.P.; Freire, F.; Santos, J.D.D.; Jorge, A.O.C.; Junqueira, J.C. Study of Microbial Interaction Formed by "Candida krusei" and "Candida glabrata": "In Vitro" and "In Vivo" Studies. Braz. Dent. J. 2017, 28, 669-674. [CrossRef] [PubMed]

81. Yang, Y.L.; Chu, W.L.; Lin, C.C.; Zhou, Z.L.; Chen, P.N.; Lo, H.J.; Hospitals, T. Mixed yeast infections in Taiwan. Med. Mycol. 2017. [CrossRef] [PubMed]

82. Zajac, D.; Karkowska-Kuleta, J.; Bochenska, O.; Rapala-Kozik, M.; Kozik, A. Interaction of human fibronectin with Candida glabrata epithelial adhesin 6 (Epa6). Acta Biochim. Pol. 2016, 63, 417-426. [CrossRef] [PubMed]

83. Munoz-Duarte, A.R.; Castrejon-Jimenez, N.S.; Baltierra-Uribe, S.L.; Perez-Rangel, S.J.; Carapia-Minero, N.; Castaneda-Sanchez, J.I.; Luna-Herrera, J.; Lopez-Santiago, R.; Rodriguez-Tovar, A.V.; Garcia-Perez, B.E. Candida glabrata survives and replicates in human osteoblasts. Pathog. Dis. 2016, 74, ftw030. [CrossRef] [PubMed]

84. Bandara, H.M.; Yau, J.Y.; Watt, R.M.; Jin, L.J.; Samaranayake, L.P. Pseudomonas aeruginosa inhibits in-vitro Candida biofilm development. BMC Microbiol. 2010, 10, 125. [CrossRef] [PubMed]

85. Baranska, M.; Kroll-Balcerzak, R.; Gil, L.; Rupa-Matysek, J.; Komarnicki, M. Successful treatment of pulmonary candidiasis and aspergillosis in patient with refractory Hodgkin lymphoma using micafungin —Case study and brief literature review. Cent. Eur. J. Immunol. 2017, 42, 111-115. [CrossRef] [PubMed]

86. Skedros, J.G.; Keenan, K.E.; Updike, W.S.; Oliver, M.R. Failed Reverse Total Shoulder Arthroplasty Caused by Recurrent Candida glabrata Infection with Prior Serratia marcescens Coinfection. Case Rep. Infect. Dis. 2014, 2014, 142428. [PubMed]

87. Klotz, S.A.; Chasin, B.S.; Powell, B.; Gaur, N.K.; Lipke, P.N. Polymicrobial bloodstream infections involving Candida species: Analysis of patients and review of the literature. Diagn. Microbiol. Infect. Dis. 2007, 59, 401-406. [CrossRef] [PubMed]

88. Klotz, S.A.; Gaur, N.K.; De Armond, R.; Sheppard, D.; Khardori, N.; Edwards, J.E., Jr.; Lipke, P.N.; El-Azizi, M. Candida albicans Als proteins mediate aggregation with bacteria and yeasts. Med. Mycol. 2007, 45, 363-370. [CrossRef] [PubMed]

89. Silva, S.; Henriques, M.; Hayes, A.; Oliveira, R.; Azeredo, J.; Williams, D.W. Candida glabrata and Candida albicans co-infection of an in vitro oral epithelium. J. Oral Pathol. Med. 2011, 40, 421-427. [CrossRef] [PubMed] 